STUDI

FRANCESI

\section{Studi Francesi}

Rivista quadrimestrale fondata da Franco Simone

170 (LVII | II) | 2013

Varia

\title{
Marie-Christine Pioffet (dir.), Dictionnaire analytique des toponymes imaginaires dans la littérature narrative de langue française (1605-1711)
}

\section{Laura Rescia}

\section{(2) OpenEdition \\ Journals}

\section{Edizione digitale}

URL: https://journals.openedition.org/studifrancesi/3072

DOI: $10.4000 /$ studifrancesi.3072

ISSN: 2421-5856

\section{Editore}

Rosenberg \& Sellier

\section{Edizione cartacea}

Data di pubblicazione: 1 juillet 2013

Paginazione: 451

ISSN: 0039-2944

\section{Notizia bibliografica digitale}

Laura Rescia, «Marie-Christine Pioffet (dir.), Dictionnaire analytique des toponymes imaginaires dans la littérature narrative de langue française (1605-1717)», Studi Francesi [Online], 170 (LVII | II) | 2013, online dal 30 novembre 2015, consultato il 02 février 2023. URL: http://journals.openedition.org/ studifrancesi/3072 ; DOI: https://doi.org/10.4000/studifrancesi.3072

Questo documento è stato generato automaticamente il 2 février 2023.

\section{c) (†) $\odot$}

Creative Commons - Attribuzione - Non commerciale - Non opere derivate 4.0 Internazionale - CC BYNC-ND 4.0

https://creativecommons.org/licenses/by-nc-nd/4.0/ 


\title{
Marie-Christine Pioffet (dir.), Dictionnaire analytique des toponymes imaginaires dans la littérature narrative de langue française (1605-1711)
}

\author{
Laura Rescia
}

\section{NOTIZIA}

MARIE-CHRISTINE PIOFFET (dir.), Dictionnaire analytique des toponymes imaginaires dans la littérature narrative de langue française (1605-1711), Québec, Presses de l'Université Laval, 2011, pp. 610.

1 Un repertorio di luoghi immaginari: così si presenta questo dizionario, alla cui redazione hanno partecipato numerosi studiosi coordinati da PIOFFET, da molti anni impegnata nella ricerca intorno a questo tema. La geografia immaginaria, spiega l'A. nell'introduzione al volume, è uno spazio topico particolarmente significativo nel Grand Siècle, alla luce delle riforme religiose, politiche e sociali che riattivano le utopie rinascimentali. Tuttavia, i luoghi utopici, per quanto compresi nel corpus, non sono i soli ad essere qui repertoriati: i romanzi, gli opuscoli allegorici e satirici, le allegorie e i racconti di viaggio sono inclusi nelle narrazioni prese in esame nel volume.

2 Più di novanta voci repertoriano questa cartografia immaginaria, delimitata cronologicamente tra il 1605, data di pubblicazione de L'Isle des Hermaphrodites di Artus Thomas, e il 1711, che segna l'apparizione della Relation du Voyage de l'Isle d'Eutopie di François Lefebvre. La definizione del corpus offre qualche difficoltà, poiché, pur escludendo le carte allegoriche e le opere liriche o epiche, ne vengono accettate alcune tra le prime, quando inserite o affiancate da uno sviluppo narrativo (come 
naturalmente la Carte du Tendre), e tra le altre (ed è il caso del Virgile travesti di Scarron) perchè trattasi di narrazioni che illustrano, secondo l'A. «les traits caractériels de la topographie morale ou satirique de l'époque».

3 Le voci si riferiscono a toponimi che solo talvolta coincidono con il titolo dell'opera: un utile indice finale aiuta il lettore nella consultazione. Spesso si è sentito il bisogno di sdoppiare o triplicare le entrate (è il caso, tra gli altri, del regno delle Amazzoni, dei Campi Elisi e della Luna): la comparazione interna è tuttavia abbondantemente utilizzata.

4 Gli articoli sono analitici, ricchi di citazioni, e seguiti da una bibliografia distinta in fonti primarie e secondarie, che viene raccolta dalla bibliografia finale. 